\title{
City Blueprints: Baseline Assessments of Sustainable Water Management in 11 Cities of the Future
}

\section{J. van Leeuwen}

Received: 11 April 2013 / Accepted: 8 October 2013 /

Published online: 13 November 2013

C) The Author(s) 2013. This article is published with open access at Springerlink.com

\begin{abstract}
The necessity of Urban Water Cycle Services (UWCS) adapting to future stresses calls for changes that take sustainability into account. Megatrends (e.g. population growth, water scarcity, pollution and climate change) pose urgent water challenges in cities. In a previous paper, a set of indicators, i.e., the City Blueprint has been developed to assess the sustainability of UWCS (Van Leeuwen et al., Wat Resour Manage 26:2177-2197, 2012). In this paper this approach has been applied in 9 cities and regions in Europe (Amsterdam, Algarve, Athens, Bucharest, Hamburg, Reggio Emilia, Rotterdam, Oslo and Cities of Scotland) and in 2 African cities in Angola (Kilamba Kiaxi) and Tanzania (Dar es Salaam). The assessments showed that cities vary considerably with regard to the sustainability of the UWCS. This is also captured in the Blue City Index (BCI), the arithmetic mean of 24 indicators comprising the City Blueprint (Van Leeuwen et al., Wat Resour Manage 26:2177-2197, 2012). Theoretically, the BCI has a minimum score of 0 and a maximum score of 10 . The actual BCIs in the 11 cities studied varied from 3.31 (Kilamba Kiaxi) to 7.72 (Hamburg). The BCI was positively correlated with the Gross Domestic Product (GDP) per person, the ambitions of the local authorities regarding the sustainability of the UWCS, the voluntary participation index (VPI) and all governance indicators according to the World Bank. The study demonstrated that the variability in sustainability among the UWCS of cities offers great opportunities for short-term and long-term improvements, provided that cities share their best practices.
\end{abstract}

Keywords Water scarcity $\cdot$ Water management $\cdot$ Climate change $\cdot$ Sustainability Water footprint $\cdot$ TRUST

\section{Introduction}

Effective water resource management and developments impacting on water resources are recognized as key components of environmentally sustainable development. The Blueprint

C. J. van Leeuwen $(\bowtie)$

KWR Watercycle Research Institute, Groningenhaven 7, 3433 PE Nieuwegein, The Netherlands e-mail: kees.van.leeuwen@kwrwater.nl

C. J. van Leeuwen

Copernicus Institute for Sustainable Development and Innovation, Utrecht University, Heidelberglaan 2, 3584 CS Utrecht, The Netherlands 
to Safeguard Europe's Water is the European Union (EU) policy response to these challenges (European Commission 2012). It aims to ensure good quality water in sufficient quantities for all legitimate uses. Cities are concentrated centers of production, consumption, and waste disposal that drive land change and a host of global environmental problems and are highly dependent on other cities and hinterlands to supply materials (including water), energy, and to dispose waste (Grimm et al. 2008; Bai 2007). Unfortunately, the blueprint to safeguard Europe's water resources fails to highlight the importance of cities as the challenges and solutions regarding sustainable water use will predominantly reside in cities (European green city index 2009; Engel et al. 2011; UN 2012; UNEP 2012). Some of these megatrends are summarized in Fig. 1.

According to the United Nations (UN) there are currently $23 \mathrm{M}$ cities (metropolitan areas with a total population in excess of 10 million people), 40 cities with 5 to 10 million inhabitants and 394 cities with 1 to 5 million inhabitants (UN 2012). Currently $52 \%$ of the human population lives in cities, and by 2050 this will be $67 \%$. In developed countries this will even rise to $86 \%$ by 2050 (UN 2012). Urban areas in the world are expected to absorb all of the population growth over the next four decades (Fig. 1). Most of the population growth expected in urban areas will be concentrated in cities and towns of less developed regions (UN 2012). With rapid population growth, water withdrawals have tripled over the last 50 years and are predicted to increase by $50 \%$ by 2025 in developing countries (SIWI 2012; UNESCO 2012). Competing demands for scarce water resources may lead to an estimated $40 \%$ supply shortage by 2030 (2030 Water Resources Group 2009). Recently, the World Economic Forum identified the water supply crisis as one of the top five global risks

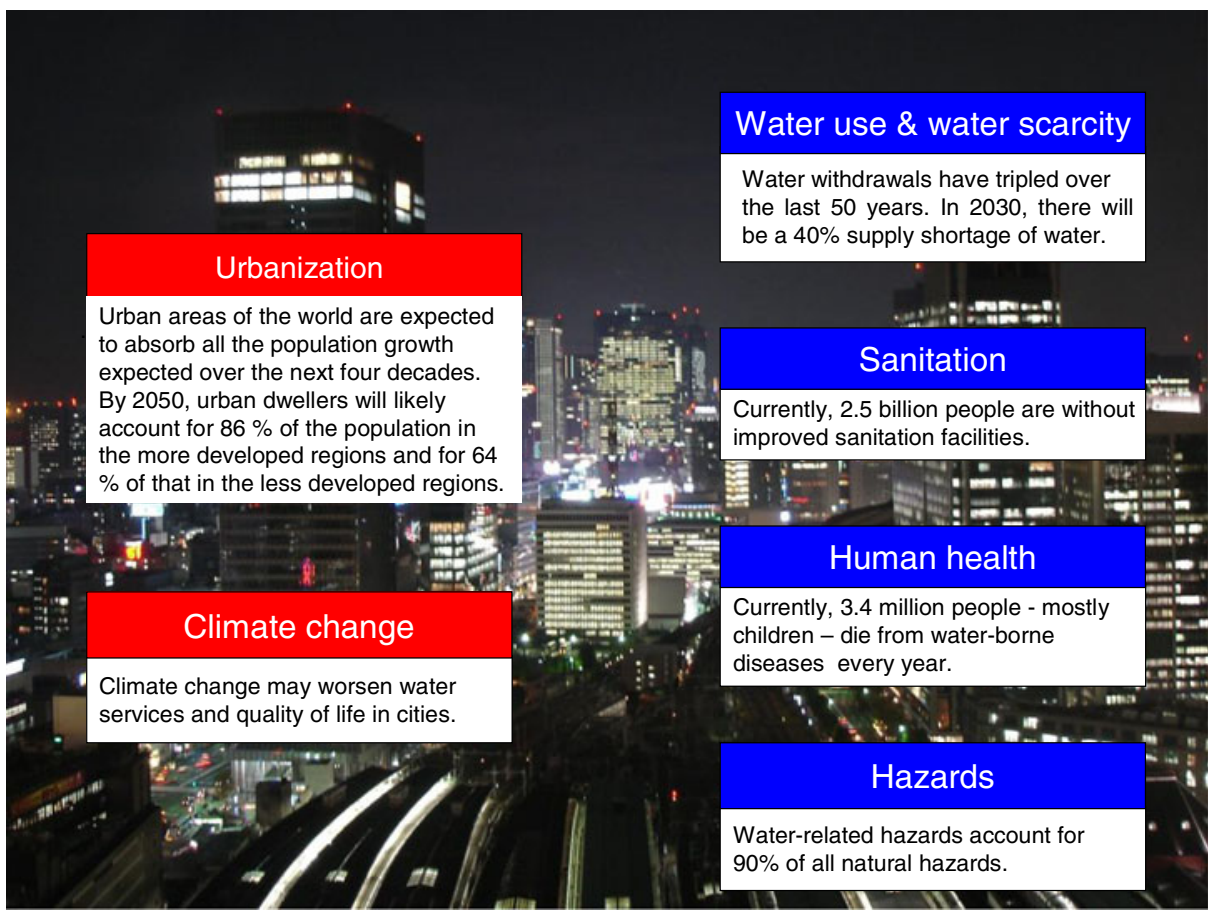

Fig. 1 Megatrends pose urgent challenges in cities 
for both the impact and likelihood. This is caused by the decline in the quality and quantity of fresh water combined with increased competition among resource-intensive systems, such as food and energy production (World Economic Forum 2013).

According to the United Nations Environment Programme (UNEP 2012), climate change, population growth and increased consumption, coupled with urbanization, are all placing increased pressure on water management. Although the Millennium Development Goal (MDG) target on water supply was met in 2010, more than 600 million people will still lack access to safe drinking water in 2015. The MDG target on sanitation is unlikely to be met, with 2.5 billion people currently without improved sanitation facilities; poor rural populations are most affected (UNEP 2012). Currently, 3.4 million people, mostly children, die annually from water-related diseases (Prüss-Üstün et al. 2008). Therefore, this global water challenge can best be addressed at the level, where these problems will concentrate, i.e. in cities.

The second reason why the focus should be on cities is water governance. According to the United Nations Development Programme (UNDP 2004), "water governance encompasses the political, economic and social processes and institutions by which governments, civil society, and the private sector make decisions about how best to use, develop and manage water resources". Governance has also emerged as a concept in political science and other fields to the growing awareness that governments are no longer the only relevant actors when it comes to the management of societal issues (Lange et al. 2013). This has recently been demonstrated for thirty European cities where a striking relation was found between the ranking based on the green city index (European green city index 2009) and the voluntary participation index (EFILWC 2006). One of the conclusions was that "The individual decisions of cities' inhabitants are, collectively, more powerful than their governments' ability to intervene" (European green city index 2009). Thus, cities are not only the problem holders but are also important to provide adequate UWCS solutions. In other words, the civil society and the private sector are crucial for the development of cities and their hinterlands and will play a major role in coping with the enormous challenges ahead.

\section{Materials and Methods}

\subsection{Cities}

The cities of Rotterdam and Dar es Salaam have been assessed previously (Van Leeuwen et al. 2012; Van Leeuwen and Chandy 2013). Additional partner cities and regions were added from the EU research project TRUST (Transitions to the Urban Water Services of Tomorrow; http:// www.trust-i.net/) leading to the following 11 cities and regions that have been included in the present study on the comparison of cities and regions: Algarve (ALG; Portugal), Amsterdam (AMS; the Netherlands), Athens (ATH; Greece), Bucharest (BUC; Romania), Dar es Salaam (DAR; Tanzania), Hamburg (HAM; Germany), Kilamba Kiaxi (KIL; Angola), Oslo (OSL; Norway), Rotterdam (ROT; the Netherlands), Reggio Emilia (REG; Italy), and the cities of Scotland (SCO; United Kingdom).

\subsection{Questionnaire}

Data gathering was organized by means of a questionnaire with 36 questions in 5 headings: (1) general information, (2) drinking water, (3) waste water, (4) environmental quality, biodiversity and attractiveness and (5) governance (Van Leeuwen and Marques 2013). 
Additional information was gathered for public participation (EFILWC 2006) and water security (Mekonnen and Hoekstra 2011), as described previously (Van Leeuwen et al. 2012).

\subsection{The Process}

Rather than collecting information ourselves, as in the case of the city of Rotterdam (Van Leeuwen et al. 2012), the stakeholders (representatives of municipalities, water utilities, wastewater utilities and water boards) were asked to complete the questionnaire in an interactive manner as described by Van Leeuwen and Chandy (2013).

\subsection{The City Blueprint}

A set of indicators, i.e., the City Blueprint, has been developed to assess the sustainability of UWCS. The City Blueprint comprises a set of 24 dedicated indicators divided over 8 categories, i.e., water security, water quality, drinking water, sanitation, infrastructure, climate robustness, biodiversity and attractiveness and governance including public participation (Van Leeuwen et al. 2012). The indicators are scored on a scale between 0 (very poor performance) to 10 (excellent performance). The City Blueprint can be used as a first step or quick-scan to benchmark the UWCS in cities (Philip et al. 2011) and may help: (1) to communicate a city's UWCS performance and exchange experiences, (2) to select appropriate water supply and sanitation strategies, (3) to develop technological and non-technological options as future alternatives for the water cycle, where several possible changes in the use of technology, space and socio-economic scenarios can be introduced. This should finally lead to: (4) a selection of measures, including an evaluation of their costs and benefits under different development scenarios, and how to integrate these in long-term planning on urban investments.

\subsection{Data Availability and Calculations}

In this study two major changes have been made compared to previous work. First of all, the lack of harmonized information for environmental quality (surface water quality, biodiversity of surface water and quality of shallow groundwater) led to the use of national data as published by the European Environment Agency (EEA 2010) and in the Environmental Performance Index (2010). Secondly, two indicators were modified. Indicator 12 now focuses on the percentage of recycled sewage sludge, i.e., sludge that is thermally processes and/or applied in agriculture. Indicator 16 (maintenance) was modified into average age of infrastructure for wastewater collection and distribution. This was done because the methodology was originally developed for the Netherlands, where the rule of thumb is that the maximum age of concrete sewer systems embedded in peaty soils should not exceed 40 years. In this study this was not longer adequate for the broader range of variations in sewer systems in Europe and Africa. In fact, the need for replacement of sewer systems is dependent amongst other things on the soil type, the pipe construction materials, pipe depth, pipe thickness and bedding conditions (Ugarelli et al. 2009).

\subsection{Blue City Index}

In order to obtain a very simple UWCS performance index for each city, the Blue City Index or BCI has been calculated. The BCI is the arithmetic mean of the 24 indicators comprising the City Blueprint and has a theoretical minimum and maximum of 0 and 10 , respectively. 


\section{Results}

\subsection{Comparison of UWCS of Cities}

Detailed information from the TRUST questionnaire and additional information gathered for water security, public participation and regional or national estimates for local environmental quality (surface water, groundwater and biodiversity), as well as the scoring of the 24 City Blueprint indicators for each city and region can be found in Van Leeuwen and Marques (2013).

\subsubsection{Drinking Water}

In general, the water quality and population coverage for drinking water services of the European cities was excellent. Prices varied from $€ 0.45$ (bulk water in Algarve) to $€ 1.77$ in Hamburg. Drinking water consumption varied considerably. In Hamburg and Amsterdam the consumption was about $50 \mathrm{~m}^{3}$ per person per year, whereas the consumption in Algarve was about three times higher $\left(146 \mathrm{~m}^{3}\right.$ per person per year). Knowledge about acceptance of alternative water resources was absent in most cases. The mains average age varied from 11 years (Algarve) to 55 year in Oslo and Reggio Emilio, although the latter figure is a rough estimate. The mains failures varied from 0.46 (Algarve) to 117.5 per $100 \mathrm{~km}$ per year (Reggio Emilia).

\subsubsection{Waste Water}

For the waste water services in Europe, the population coverage varied from $90 \%$ (Reggio Emilia) to $99.5 \%$ for Oslo. Most of the systems were collection, transport and treatment systems. Energy recovery from waste water takes place in all European cities except for Algarve and Bucharest. Nutrient recovery is an exception and only takes place in Hamburg and Reggio Emilia. Unfortunately, no information is available for Scotland for both energy and nutrient recovery from waste water. The total energy costs varied from $€ 0.7$ million (covering 325,000 connections) to $€ 23.6$ million in Scotland (covering 2,460,000 connections). The energy costs per connection varied from $€ 0.44$ (Oslo) to $€ 19.6$ (Athens). Most cities process their sewage sludge thermally, but some cities in Scotland, the city of Reggio Emilia and the cities in Algarve, apply their sludge in agriculture. In some places in Scotland and in the Algarve small fractions of the sewage sludge is going into landfill. In Bucharest all sewage sludge is going into landfill. The average age of the sewer systems varied from 11 (Algarve) to 55 years (Oslo). The number of sewage blockages varied from 0.5 (per $100 \mathrm{~km}$ ) in Algarve to 577 in Bucharest. The separation of sanitary and storm water sewers showed a large variation. It varied from $0 \%$ for Algarve to $83 \%$ for Amsterdam. The separation was even higher for Athens $(97 \%)$.

\subsubsection{City Blueprints}

A simple diagram has been made to highlight the most important features of UWCS in cities. This diagram is called the City Blueprint (Van Leeuwen et al. 2012) in line with the European Commission's "Blueprint to Safeguard Europe's Water Resources" (European Commission 2012), but highlighting the importance of cities. The scores for all indicators of the City Blueprint for all cities and regions are presented in Van Leeuwen and Marques (2013). Blueprints for 6 cities are given in Fig. 2. 


\section{Kilamba Kiaxi (3.31)}

\section{Water footprint}

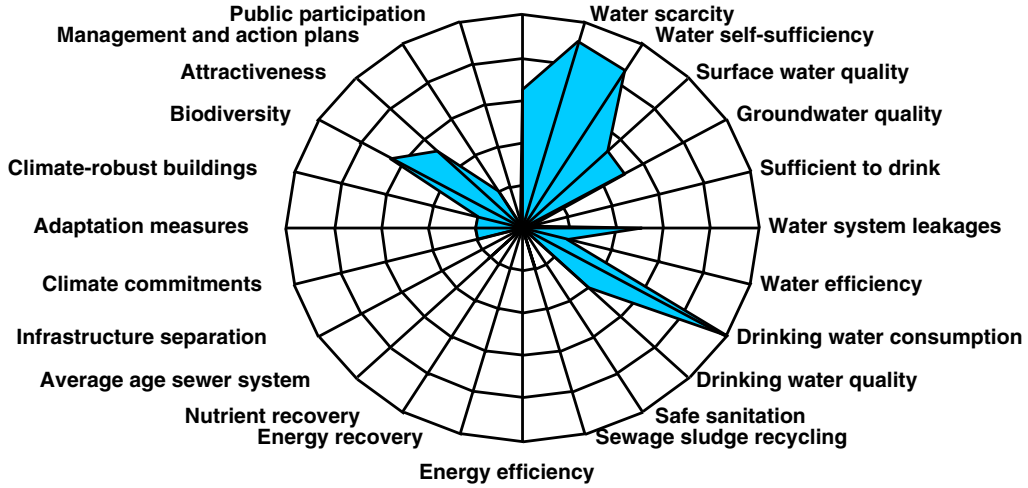

\section{Dar es Salaam (4.01)}

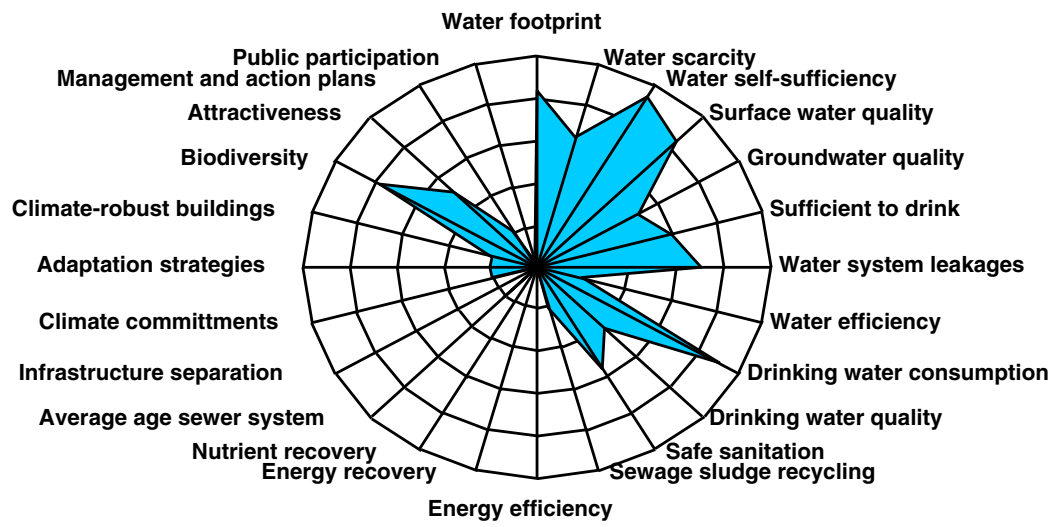

\section{Bucharest (5.18)}

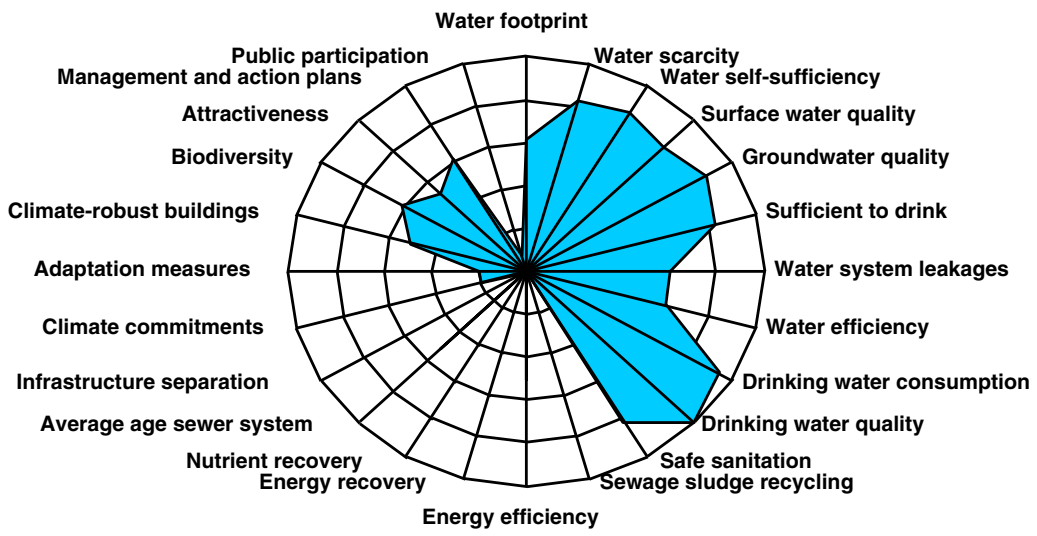

Fig. 2 City Blueprints for 6 cities with increasing BCIs (in parentheses): Kilamba Kiaxi (3.31), Dar es Salaam (4.01), Bucharest (5.18), Athens (6.26), Amsterdam (7.43) and Hamburg (7.72) 


\section{Athens (6.26)}

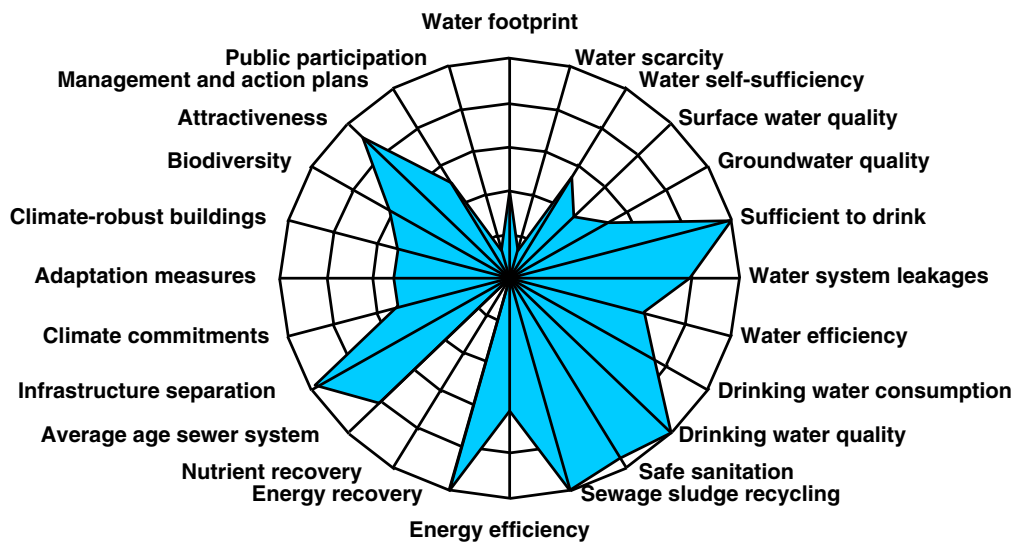

\section{Amsterdam (7.43)}

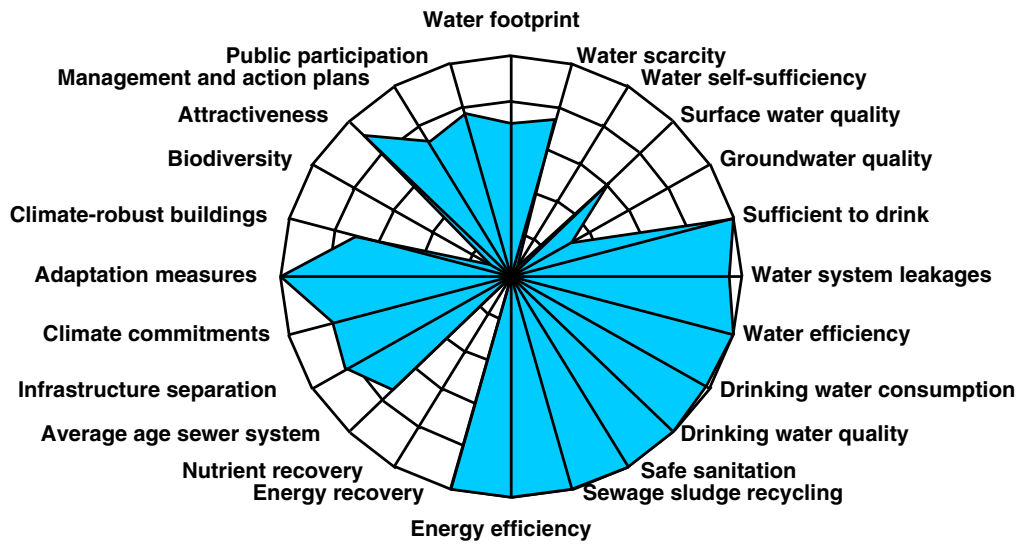

\section{Hamburg (7.72)}

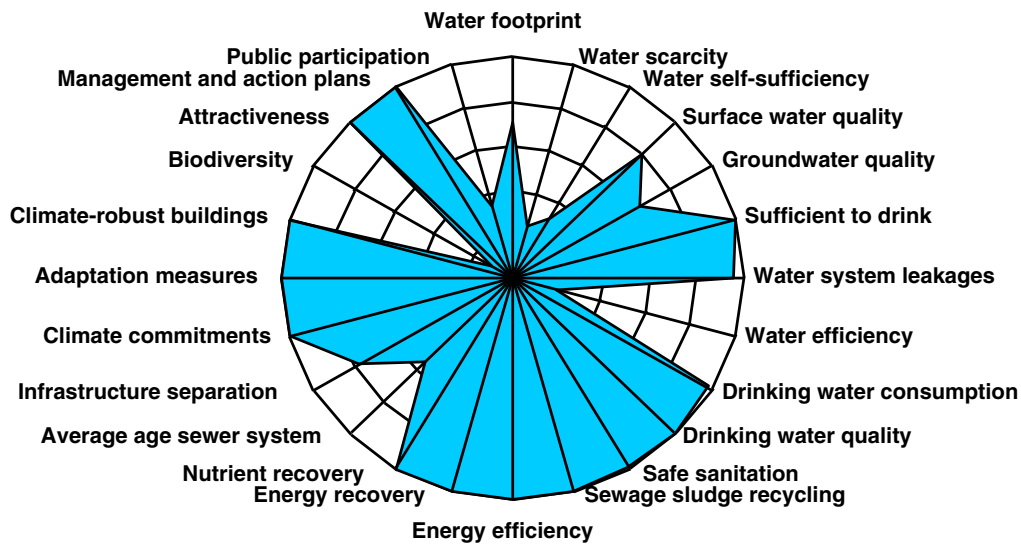

Fig. 2 (continued) 
Table 1 Summary information about the BCI, UWCS management and action plans (indicator 23) for cities/ regions and various national indexes from the IMF (2012) and World Bank (2013) Abbreviations: see text

\begin{tabular}{llllllll}
\hline City/region & BCI & UWCS & VPI & GDP & GE & RQ & RL \\
\hline Algarve & 5.61 & 6 & 1 & 23363 & 78.7 & 73.9 & 81.7 \\
Athens & 6.26 & 5 & 1.3 & 26258 & 66.8 & 69.7 & 66.7 \\
Reggio Emilia & 6.60 & 6 & 1.7 & 30464 & 66.4 & 75.4 & 63.4 \\
Amsterdam & 7.43 & 7 & 7.7 & 42023 & 96.7 & 98.1 & 97.7 \\
Hamburg & 7.72 & 10 & 3.3 & 38077 & 91.9 & 92.9 & 91.5 \\
Oslo & 7.41 & 7 & 10 & 53396 & 96.2 & 91 & 98.1 \\
Scotland & 6.23 & 6 & 3.3 & 36522 & 92.4 & 94.3 & 92.5 \\
Bucharest & 5.18 & 6 & 0.7 & 12493 & 47.4 & 74.9 & 56.3 \\
Rotterdam & 7.03 & 8 & 7.7 & 42023 & 96.7 & 98.1 & 97.7 \\
Kilamba Kiaxi & 3.31 & 2 & 0.15 & 5924 & 11.4 & 12.3 & 10.3 \\
Dar es Salaam & 4.01 & 2 & 0.3 & 1610 & 36.5 & 35.5 & 34.3 \\
\hline
\end{tabular}

\subsubsection{Blue City Index (BCI)}

The data for the BCI of each city or region are given in Table 1, together with some other indicators such as the scores for the commitments for UWCS (indicator 23), the VPI (voluntary participation index) according to the EFILWC (2006), and the GDP (Gross Domestic Product) per capita (in international dollars for 2011) as reported by the International Monetary Fund (IMF 2012). Comparisons were also made with some governance indicators according to the World Bank (2013) such as the GE (Government Effectiveness), RQ (Regulatory Quality) and RL (Rule of Law) as described by Kaufman et al. (2010). The RL is a national indicator capturing perceptions of the extent to which agents have confidence in and abide by rules of society, and in particular the quality of contract enforcement, property rights, the police, the courts, as well as the likelihood of crime and violence (Kaufman et al. 2010).

Like in the European green city index (2009), there is a positive relation between the performance of the cities regarding their water services (BCI) and the VPI (indicator 24). The Pearson correlation coefficient ( $\mathrm{r}$ ) is 0.727 . The BCI also correlates well with the UWCS commitments (indicator 23) of the cities/regions $(r=0.904)$. Statistically this is not fully correct as indicators 23 and 24 are part of the BCI and therefore the data are not completely independent from each other. The BCI also shows a strong correlation with GDP $(r=0.927$;

Fig. 3 The relation between the BCI (blue city index) and the GDP per capita (IMF 2012)

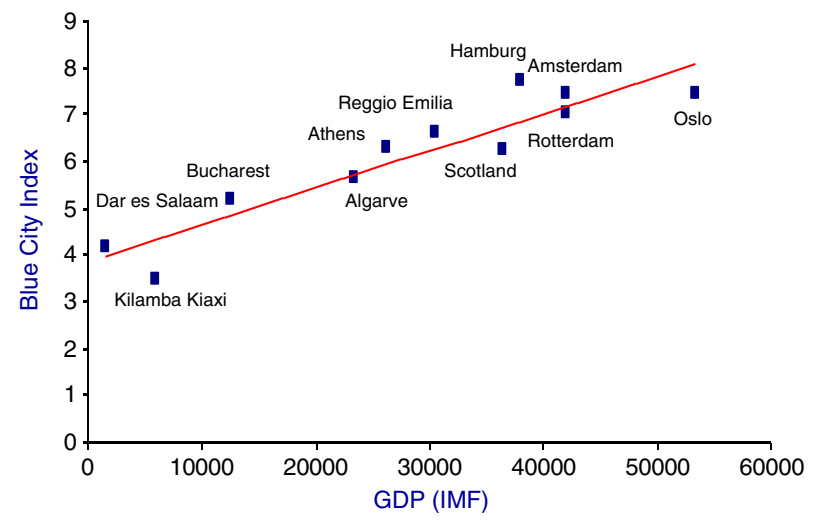


Fig. 4 The relation between the BCI (blue city index) and government effectiveness (World Bank 2013)

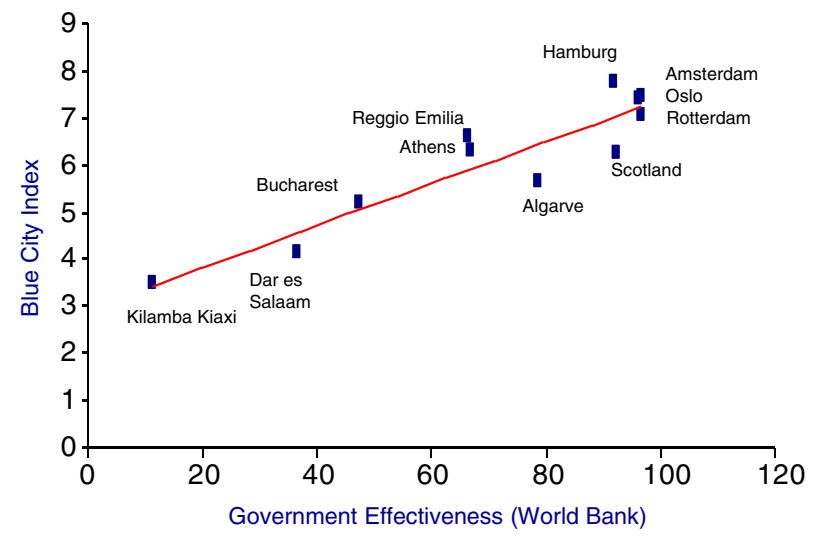

Fig. 3) and the governance indicators of the World Bank, for instance GE (Fig. 4). The correlation coefficient for the BCI and GE, RQ and RL was 0.927, 0.921 and 0.917, respectively. Further analysis of other World Bank Indicators has not been performed as all World Bank indicators for the subset in this report (11 cities in 10 countries) intercorrelate strongly. This is shown in Table 2, where also another World Bank indicator has been included, i.e. voice and accountability (VA). VA captures perceptions of the extent to which a country's citizen are able to participate in selecting their government, as well as freedom of expression, freedom of association, and a free media (Kaufman et al. 2010). These high intercorrelations are demonstrated for e.g. RL and GE (0.994) and RL and RQ (0.967).

\subsection{Implementation of Best Practices in Cities}

In Table 3 the City Blueprint indicators are listed together with the best performing cities. In the third column the best score per indicator is given, to indicate what the current best practices are. In order to illustrate this further, a City Blueprint is provided in which all the best practices (best scores from Table 3) are given. This is shown in Fig. 5. It shows that cities can learn from each other and that active exchange of "best practices", can significantly improve the sustainability of UWCS of cities.

Table 2 Pearson correlation matrix for the indicators of 11 cities and/or regions in 10 different countries. Abbreviations: see text

\begin{tabular}{lllllllll}
\hline & BCI & VPI & UWCS & GDP & GE & RQ & VA & RL \\
\hline BCI & X & 0.727 & 0.904 & 0.927 & 0.927 & 0.921 & 0.860 & 0.917 \\
VPI & 0.727 & X & 0.571 & 0.867 & 0.746 & 0.670 & 0.553 & 0.742 \\
UWCS & 0.904 & 0.571 & X & 0.794 & 0.842 & 0.887 & 0.795 & 0.856 \\
GDP & 0.927 & 0.867 & 0.794 & X & 0.918 & 0.858 & 0.821 & 0.905 \\
GE & 0.927 & 0.746 & 0.842 & 0.918 & X & 0.951 & 0.917 & 0.994 \\
RQ & 0.921 & 0.670 & 0.887 & 0.858 & 0.951 & X & 0.891 & 0.967 \\
VA & 0.860 & 0.553 & 0.795 & 0.821 & 0.917 & 0.891 & X & 0.919 \\
RL & 0.917 & 0.742 & 0.856 & 0.905 & 0.994 & 0.967 & 0.919 & X \\
\hline
\end{tabular}


Table 3 Indicators, lowest and highest scores and best performing cities/regions

\begin{tabular}{|c|c|c|c|}
\hline Indicator & Lowest score & Best score & Best performing cities \\
\hline 1 Total water footprint & 3.4 & 8.4 & DAR, SCO, OSL \\
\hline 2 Water scarcity & 1.3 & 9.8 & OSL, KIL, BUC \\
\hline 3 Water self-sufficiency & 0.54 & 9.3 & DAR, KIL, BUC \\
\hline 4 Surface water quality & 4 & 9.5 & OSL, DAR \\
\hline 5 Groundwater quality & 3 & 9.8 & OSL, BUC \\
\hline 6 Sufficient to drink & 6 & 10 & ATH, AMS, HAM, OSL, ROT \\
\hline 7 Water system leakages & 5 & 9.6 & HAM, AMS, ROT \\
\hline 8 Water efficiency & 2 & 10 & REG, AMS, ROT \\
\hline 9 Drinking water consumption & 5.4 & 10 & ROT, KIL \\
\hline 10 Drinking water quality & 4 & 10 & REG, AMS, BUC \\
\hline 11 Safe sanitation & 0 & 10 & OSL, AMS \\
\hline 12 Recycling of sewage sludge & 0 & 10 & $\begin{array}{l}\text { ATH, REG, AMS, HAM, OSL, } \\
\text { ROT }\end{array}$ \\
\hline 13 Energy efficiency & 0 & 10 & AMS, HAM \\
\hline 14 Energy recovery & 0 & 10 & ATH, AMS, HAM \\
\hline 15 Nutrient recovery & 0 & 10 & REG, HAM \\
\hline 16 Average age & 2 & 8.9 & ALG, ATH \\
\hline $\begin{array}{l}17 \text { Separation of waste water and storm } \\
\text { water }\end{array}$ & 0 & 9.7 & ATH, AMS \\
\hline 18 Commitments to climate change & 2 & 10 & HAM, ROT \\
\hline 19 Adaptation measures & 2 & 10 & AMS, HAM, ROT \\
\hline 20 Climate-robust buildings & 2 & 10 & HAM \\
\hline 21 Biodiversity & 1 & 7.8 & DAR \\
\hline 22 Attractiveness & 5 & 10 & HAM, OSL, AMS \\
\hline 23 Management and action plans & 2 & 10 & HAM \\
\hline 24 Public participation & 0.15 & 10 & OSL \\
\hline
\end{tabular}

\section{Discussion}

\subsection{Methodological Aspects}

The key characteristics of a good indicator are: (1) easy to access, (2) easy to understand, (3) timely and relevant, (4) reliable and consistent, (5) credible, transparent and accurate, and (6) developed with the end-user in mind (Norman et al. 2010). The choice of indicators is per definition subjective. There are many options for other indicators and a variety of methods to quantify them. However, the selected questions and indicators provide for a good overview of the key sustainability issues in UWCS.

From a methodological point of view, there are options to improve the way the assessments have been made. The scores of the cities are dependent on data availability and quality. This is a major issue. In fact, the baseline assessment of the cities has shown that the choice of the indicators is partly driven by the availability, quality and comparability of the input data. In a couple of cases no local information could be provided, and assessments were based on regional or national information (Van Leeuwen et al. 2012; Van Leeuwen and Chandy 2013). In some cases there was no information at all and expert judgment scores or 


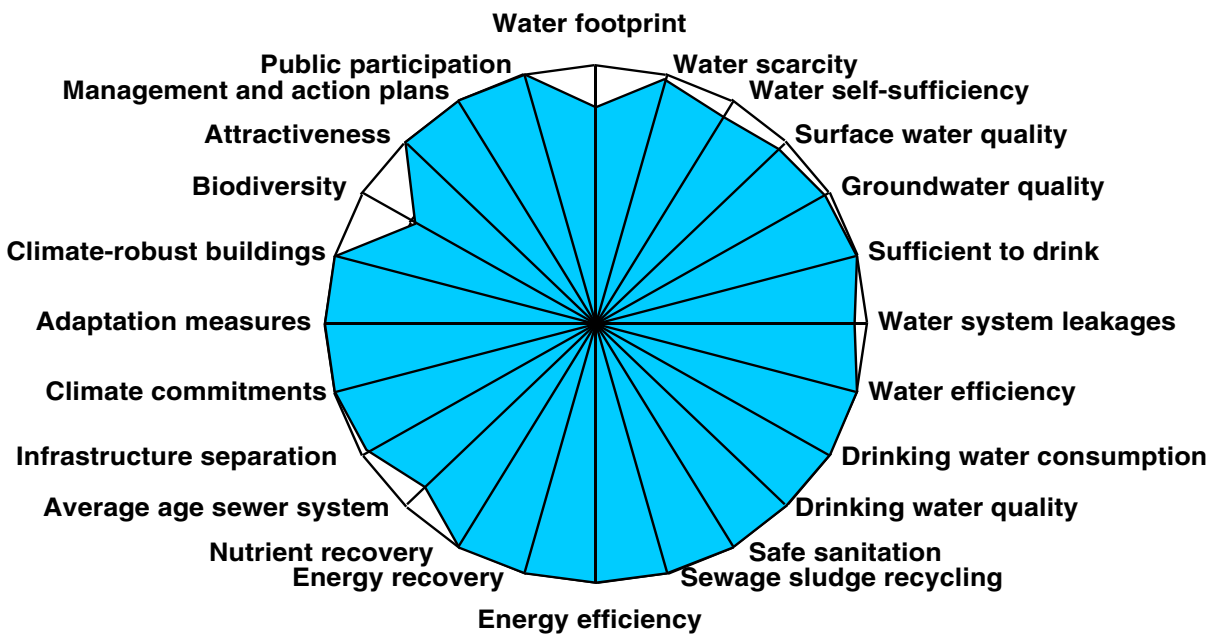

Fig. 5 City blueprint of a city that has implemented all current best practices (highest scores per indicator as listed in Table 3)

best professional "guesstimates" have been provided. For instance, the water security, environmental quality and public participation (VPI) data have been obtained from regional or national data sources. Depending on the size of the country and regional differences in e.g. precipitation, soil type, pollution and governance, the use of these regional/national data may lead to errors in the assessment of the local situation.

In the discussions with the stakeholders in cities it became obvious that priorities based on an assessment following the City Blueprint approach are viewed differently as priorities are set in their local political, economic and social contexts. As the City Blueprint assessment is only a baseline assessment (Philip et al. 2011) and can, and very often should, be followed by more refined analysis of particular aspects of UWCS, a pragmatic decision was taken not to attribute different weights to the indicators at this preliminary assessment stage. Every indicator has thus received the same weight, resulting in a BCI with a theoretical minimum of 0 and maximum of 10 .

The use of national or regional information on environmental quality as used in this report may lead to serious overestimations of local environmental quality as cities are often sources of pollution (Grimm et al. 2008; Bai 2007). The use of local information rather than national data on e.g. water quality in the case of Rotterdam (Van Leeuwen et al. 2012) and Dar es Salaam (Van Leeuwen and Chandy 2013) leads to much lower scores and are clear examples of this. In other words the scores as provided in the current paper on environmental quality are probably too optimistic and are underestimations of the actual environmental quality of the cities. Furthermore, many water pollutants have not been accounted for. The Environmental Performance Index (2010) uses only three parameters measuring nutrient levels (dissolved oxygen, total nitrogen, and total phosphorus) and two parameters measuring water chemistry ( $\mathrm{pH}$ and conductivity). These parameters were selected because they cover issues of global relevance (eutrophication, nutrient pollution, acidification, and salinization) and because they are the most consistently reported. The consequence of this is that important groups of chemicals such as persistent organic pollutants (POPs), persistent bioaccumulating and toxic chemicals (PBTs), endocrine disrupters and many other groups of micro-pollutants have not been addressed at all. This may lead to a serious underestimation of the actual pollution status in cities. 
Retrospectively, it would have been better to be more specific about climate change. Climate change can mean different things to different people. It may implicitly address related, but totally different issues such as: (1) concrete greenhouse gas reduction targets, (2) safety; i.e. adaptation strategies and measures against flooding, (3) water security; i.e. measures to combat water scarcity, (4) measures to increase green cover (park, trees and agricultural surfaces in urban areas) to reduce the "heat island" effects. Answers on this question have been used to score indicators 18 (climate commitments) and 19 (safety). Cities may put different priorities to these aspects.

While water is generally abundant in much of Europe, water scarcity and droughts continue to affect some areas. Water scarcity and droughts have direct impacts on citizens and economic sectors. Activities with high water demand, such as irrigated agriculture, industrial production and the use of cooling water, are heavily affected by water scarcity. The current indicators do not optimally address the complexities of water scarcity (Hoekstra et al. 2012). Further information on water scarcity for Europe is provided by the Water Exploitation Index (WEI) as presented by the EEA (2010).

\subsection{The Strength and Limitations of the City Blueprint}

The City Blueprint is a baseline assessment and quick scan for the sustainability of the UWCS. Early involvement of stakeholders is important (Van Leeuwen 2007; Van Leeuwen and Chandy 2013). The City Blueprint method and process is proposed as first step of gaining a better understanding of UWCS and the challenges ahead (Philip et al. 2011). This has been accomplished. The inherent limitations are that the baseline assessment does not cover all aspects of the UWCS. Some aspects of UWCS are addressed very generally. The assessment is also a snapshot. It is a picture and, therefore, does not address long-term trends in UWCS stress and adaptations. In other words, the assessment is static and not dynamic. In discussions with the cities of Oslo, Athens and Dar es Salaam, the representatives explained that more drinking water needs to be provided in the very near future (Rozos and Makropoulos 2013; Van Leeuwen and Chandy 2013). For instance, in the city of Dar es Salaam in Tanzania the population is expected to double in size in the next decade! These trends are not captured in the City Blueprint. Furthermore, the current political situation in Greece precludes long-term planning and investment strategies in UWCS and is so uncertain that, in contrast with the global trend (Fig. 1) people are leaving the city of Athens and move to rural areas. This actually leads to a decrease in the number of city inhabitants. Finally, drinking water consumption in Algarve is very high $\left(146 \mathrm{~m}^{3}\right.$ per person per year). This may be explained by the high influx of tourists, whereas the calculation for drinking water consumption is based on the registered population. All these observations need to be included in the city reports. When these limitations are taken into account, the City Blueprint provides stakeholders with a basic insight in the current status of the sustainability of their UWCS. It enables them to internally reflect upon the current status in terms of possible consequences for future UWCS management, to share the results with other UWCS stakeholders, and to discuss potential improvements.

\subsection{Towards Implementation of Best Practices}

The fastest route to failure in the transition towards sustainable cities would be to sit and wait for e.g. the ultimate technological breakthroughs in water technology. This is not recommended. There is a need for a two-stage approach. The first challenge is to start the discussion with all 
stakeholders, to enhance public participation and to translate the baseline assessments into actions to improve the UWCS of cities based on currently available technologies (Fig. 5; Makropoulos and Butler 2010). This is an enormous challenge. However, climate change, population growth and changes in consumption patterns are projected to further increase water shortages. Improving cities on the basis of current technologies will most likely be insufficient to cope with these trends and challenges ahead. Therefore, the second challenge is to continue technological research to further improve the sustainability of UWCS. This baseline survey of UWCS can be used for a variety of purposes to:

- Aid in the evaluation and compare outcomes with other cities.

- Translate knowledge and educate.

- Raise/improve awareness (particularly in communicating with the public).

- Enable informed decision-making, i.e. to identify priorities and budgets (planning).

- Refine parts of the assessment, with tailor-made in-depth studies and advanced models, if necessary.

- Monitor progress.

- Stimulate the exchange of best practices for UWCS (UNEP 2008; De Graaf et al. 2007a,b).

Although there are clear differences among the UWCS of the cities in this report, the most important conclusion from this study is that cities can learn from each other. The learning potential would theoretically allow an increase in the range of BCI scores from 3.31 (Kilamba Kiaxi) and 7.72 (Hamburg) to 9.70 (Fig. 5), based on current technologies. This result can be used in the transitions of UWCS in cities as described by Brown et al. (2009). It is important to realize that the implementation of "best practices" for some of these indicators-such as the water scarcity related indicators (1-3) is easier said than done. Water scarcity is not only determined by human behavior, but also by large-scale climatic, geological and hydrological processes. On the other hand, almost all indicators can be influenced directly at the level of the city.

\subsection{Next Steps}

Hundreds of millions of people in urban areas across the world will be affected by climate change. The vulnerability of human settlements will increase through rising sea levels, inland floods, frequent and stronger tropical cyclones, and periods of increased heat and the spread of diseases. Climate change may worsen the access to basic urban services and the quality of life in cities. Most affected are the urban poor-the slum dwellers in developing countries (UN-Habitat 2010). This probably also holds for Europe, where climate change is projected to increase water shortages, particularly in the Mediterranean region (EEA 2012). These megatrends pose urgent challenges in cities (Fig. 1; Engel et al. 2011). One of the follow-up actions in the context of UWCS would be to develop a simple tool for the estimation of the costs and benefits of measures to improve UWCS. Another priority would be to refocus the plans of the European Commission regarding the Blueprint to Safeguard Europe's Water with more focus on cities. Cities should become part of the solution.

The fastest way to meet the global water challenges is not another policy document, but active and timely information exchange. This can be stimulated by more transparent communication, more focus on public awareness as well as on implementation of available technologies (Fig. 5). Examples are the creation of a Blue City website where cities can display their best practices regarding UWCS, a Blue Friend Label for 
industries and their products contributing to cost-effective improvements in UWCS, and an annual Blue City Award for the best performing city. By enabling this, sustainable development will take place, cities will start to learn from each other, and civil society and the private sector can play their role (European green city index 2009). Recently, this City Blueprint proposal on governance has been prioritized by the European Commission in the context of the European Innovation Partnership on Water (European Commission 2013).

\section{Conclusions}

The City Blueprints, i.e. the baseline assessments for UWCS for 11 cities/regions as presented in this report show that the cities vary considerably with regard to the sustainability of the UWCS. This is captured in the Blue City Index (BCI), the arithmetic mean of 24 indicators comprising the City Blueprint (Table 1). The BCI varied from 3.31 (Kilamba Kiaxi) to 7.72 (Hamburg). Although correlation coefficients are no cause-effect relationships, cities with the best BCI are cities:

- With an active civil society expressed as VPI $(r=0.727)$

- With high UWCS commitments $(r=0.904)$

- In countries with a high GDP $(r=0.927)$

- In counties with a high governance effectiveness $(r=0.927)$

An important result from this study is that the variability in sustainability among the UWCS of the cities offers great opportunities for short-term and long-term improvements, provided that cities share their best practices (UNEP 2008). Cities can learn from each other (Fig 5). Theoretically, if cities would share their best practices, the BCI might reach a value of 9.70 , which is close to the theoretical maximum of 10 . It shows that even cities that currently perform well, can still improve their UWCS. Of course, this would depend on many other factors, such as socio-economic and political considerations (Van Leeuwen 2007), and is ultimately the responsibility of the cities themselves. The ideas presented in this paper have recently been prioritized as action by the European Commission in the context of the European Innovation Partnership on Water (European Commission 2013).

Acknowledgments This work has been carried out as institutional research of KWR Watercycle Research Institute in the context of Watershare ${ }^{\circledR}$ : sharing knowledge in the water sector (http://www.kwrwater.nl/ watershare/). The methodology has been applied in the context of the EU Research Project TRUST (Transitions to the Urban Water Services of Tomorrow). I would like to thank all collaborative teams involved in the assessment of cities by completing the questionnaire for the baseline assessment and their feedback on earlier versions of this document: Helena Lucas, José Gascão, Joaquim Freire, Maria João Freitas, António Jorge Monteiro, Christos Makropoulos, Vittorio Di Federico, Thomas Giese, Kim Augustin, Niels-Peter Bertram, Ingrid Heemskerk, Paulien Hartog, Brian Sewbaks, Jadranka Milina, Rita Ugarelli, Paul Jeffrey, Heather Smith, George Ponton, Colin O’Neill, Gabriela Mercore, Daniel Goedbloed, António Jorge Monteiro and Philipo Chandy. I would also like to thank Marielle van de Zouwen, Jos Frijns, Theo van de Hoven, Peter Dane, Merijn Schriks, Nicoline Scholman, Rui Cunha Marques, Sveinung Sagrov, and the project leader of TRUST, i.e. David Schwesig for their major contributions to the work described in this manuscript. The European Commission is acknowledged for funding TRUST in the 7th Framework Programme under Grant Agreement No. 265122.

Open Access This article is distributed under the terms of the Creative Commons Attribution License which permits any use, distribution, and reproduction in any medium, provided the original author(s) and the source are credited. 


\section{References}

Bai X (2007) Industrial ecology and the global impacts of cities. J Industr Ecol 11:1-6

Brown RR, Keath N, Wong THF (2009) Urban water management in cities: Historical, current and future regimes. Water Sci Technol 59:847-855

De Graaf R, van de Giessen N, van de Ven F (2007a) Alternative water management options to reduce vulnerability for climate change in the Netherlands. Nat Hazards 5:407-422

De Graaf RE, van de Giessen NC, van de Ven FHM (2007b) The closed city as a strategy to reduce vulnerability of urban areas for climate change. Water Sci Technol 56:165-173

EEA (2010) European Environment Agency. The European environment. State and outlook 2010. Synthesis. Copenhagen, Denmark

EEA (2012) European Environment Agency. Urban adaptation to climate change in Europe. Challenges and opportunities for cities together with supportive national and European policies. Synthesis, Copenhagen, Denmark

EFILWC (2006) First European quality of life survey: participation in civil society. European Foundation for the Improvement of Living and Working Conditions, Dublin. http://www.eurofound.europa.eu/publications/ htmlfiles/ef0676.htm. Accessed 21 February 2011

Engel K, Jokiel D, Kraljevic A, Geiger M, Smith K (2011) Big cities. Big water. Big challenges. Water in an urbanizing world. World wildlife fund, Koberich

Environmental Performance Index (2010) http://www.epi2010.yale.edu/Metrics/WaterEffectsOnEcosystem. Accessed 30 March 2012

European Commission (2012) Communication from the Commission to the European Parliament, the Council, the European Economic and Social Committee and the Committee of the Regions. A Blueprint to Safeguard Europe's Water Resources. COM (2012)673 final

European Commission (2013) European Innovation Partnership on water (EIP Water). http://ec.europa.eu/ environment/water/innovationpartnership/

European green city index (2009) Assessing the environmental impact of Europe's major cities. A research project conducted by the Economist Intelligence Unit, http://www.siemens.com/press/pool/de/events/ corporate/2009-12-Cop15/European_Green_City_Index.pdf. Accessed 20 February 2011

Grimm NB, Faeth SH, Golubiewski NE, Redman CL, Wu J, Bai X, Briggs JM (2008) Global change and the ecology of cities. Science 319(5864):756-760

Hoekstra AY, Mekonnen MM, Chapagain AK, Mathews RE, Richter BD (2012) Global monthly water scarcity: Blue water footprints versus blue water availability. PLoS ONE 7(2):e32688. doi:10.1371/ journal.pone. 0032688

IMF (2012) Gross Domestic Product (international dollars) as provided by the International Monetary Fund for 20102011: http://en.wikipedia.org/wiki/List_of_countries_by_GDP_(PPP)_per_capita. Accessed October 2012

Kaufman D, Kraay A, Mastruzzi M (2010) The worldwide governance indicators. Methodology and analytical issues. World Bank Policy Research Working Paper 5430. World Bank, Washington DC

Lange P, Driessen PJ, Sauer A, Borneman B, Burger P (2013) Governing towards sustainability conceptualizing modes of governance. J Environ Policy Planning 15:403-425

Makropoulos CK, Butler D (2010) Distributed water infrastructure for sustainable communities. Water Resour Manag 24(11):2795-2816

Mekonnen MM, Hoekstra AY (2011) National water footprint accounts: the green, blue and grey water footprint of production and consumption. Volumes 1 and 2. Value of Water Research Report Series No. 50. UNESCO-IHE, Delft, the Netherlands

Norman E, Bakker K, Cook C, Dunn G, Allen D (2010) Water security: A primer. Policy report. Fostering water security in Canada Project www.watergovernance.ca Accessed 20 September 2013

Philip R, Anton B, van der Steen P (2011) SWITCH training kit. Integrated urban water management in the city of the future. Module 1. Strategic planning, ICLEI, Freiburg, Germany

Prüss-Üstün A, Bos R, Gore F, Bartram J (2008) Safer water, better health: Costs, benefits and sustainability of interventions to protect and promote health. World Health Organization, Geneva

Rozos E, Makropoulos C (2013) Source to tap urban water cycle modelling. Environ Model Softw 41:139-150

SIWI (2012) Stockholm International Water Institute. Statistics. http://www.siwi.org/sa/node.asp?node=159 Accessed 20 December, 2012

Ugarelli R, Pachioli M, Di Federico V (2009) Planning maintenance strategies for Italian urban drainage systems applying CARE-S. In: Allegre H, do Céu Almeida M (eds) Strategic asset management of water supply and wastewater infrastructures. IWA Publishing, London, pp 471-486

UN (2012) World urbanization prospects: The 2011 revision. UN, New York, USA. http://esa.un.org/unup/. Accessed 30 November 2012

UNDP (2004) Water governance for poverty reduction. USA, New York 
UNEP (2008) Every drop counts; environmentally sound technologies for urban and domestic water use efficiency. Switzerland, Geneva

UNEP (2012) Fifth global environment outlook: Environment for the future we want. Switzerland, Geneva

UNESCO (2012) Managing water under uncertainty and risk. Facts and figures from the UN world water development report 4. http://unesdoc.unesco.org/images/0021/002154/215492e.pdf. Accessed 20 December 2012

UN-Habitat (2010). Climate change strategy 2010-2013. Urban Environmental Planning Branch, Nairobi, Kenia. http://www.google.nl/search?sourceid=navclient\&ie=UTF-8\&rlz=1T4MXGB enNL512NL512\&q=Climate+ change+strategy+2010-2013. Accessed 20 December 2012

Van Leeuwen CJ (2007) Introduction. In: Van Leeuwen CJ, Vermeire TG (eds) Risk Assessment of Chemicals. An Introduction. Springer, Dordrecht, 2nd edn, pp. 1-36

Van Leeuwen CJ, Frijns J, Van Wezel A, Van De Ven FHM (2012) City blueprints: 24 indicators to assess the sustainability of the urban water cycle. Wat Resour Manage 26:2177-2197

Van Leeuwen CJ, Chandy PC (2013) The city blueprint: Experiences with the implementation of 24 indicators to assess the sustainability of the urban water cycle. Water Sci Technol 13(3):769-781

Van Leeuwen K, Marques RC (2013) Current state of sustainability of urban water cycle services. Transition to the Urban Water Services of tomorrow (TRUST) report D11.1. http://www.trust-i.net/downloads/ index.php?iddesc $=68$

2030 Water Resources Group (2009) Charting our water future. Economic framework to inform decisionmaking. West Perth, USA. http://www.mckinsey.com/App_Media/Reports/Water/Charting_Our_Water_Future_Full_ Report 001.pdf. Accessed 20 February 2011

World Bank (2013) Worldwide Governance Indicators. http://info.worldbank.org/governance/wgi/index.asp. Accessed 30 March 2013.

World Economic Forum (2013) Global Risks, 8th edn. Geneva, Switzerland. http://reports.weforum.org/ global-risks-2013/ Accessed 30 March 2013 